\title{
Diabetes and Hypertension in a Santhal Tribe in Bangladesh: A Population Based Study
}

\author{
M. Abu Sayeed ${ }^{*}$, Parvin Akter Khanam², Muhammad Tofazzal Hussain', \\ Mir Masudur Rhaman'1, Shurovi Sayeed ${ }^{3}$, Tanjima Begum², \\ M. Abu Hana Golam Morshed ${ }^{2}$, Akhter Banu ${ }^{3}$ \\ ${ }^{1}$ Department of Community Medicine, Ibrahim Medical College, Dhaka, Bangladesh \\ ${ }^{2}$ Department of Epidemiology, BIRDEM, Dhaka, Bangladesh \\ ${ }^{3}$ Institute of Nutrition and Food Science, University of Dhaka, Dhaka, Bangladesh \\ Email: sayeed1950@gmail.com
}

Received 17 April 2014; revised 10 May 2014; accepted 18 May 2014

Copyright (C) 2014 by authors and Scientific Research Publishing Inc. This work is licensed under the Creative Commons Attribution International License (CC BY). http://creativecommons.org/licenses/by/4.0/

c) (i) Open Access

\section{Abstract}

BACKGROUND: Santhal (Santals) tribe is one of the oldest and largest aboriginal pre Aryan populations in India and Bangladesh. There was no published report on the prevalence of diabetes and hypertension. OBJECTIVE: To determine the prevalence of type 2 diabetes mellitus (T2DM) and hypertension in a Santhal tribe of Bangladesh. RESEARCH DESIGN AND METHODS: Eight villages inhabited largely by Santhal tribe were purposively selected. All Santhals aged 20 years or more were considered eligible and enlisted for the study. Investigations included socio-demographic information (age, sex, education, income), clinical history (general illness), anthropometry (height, weight, waist-girth, hip-girth) and blood pressure. Body mass index (BMI) and waist-to-hip ration (WHR) were calculated. Blood samples were collected for fasting plasma glucose (FPG), total cholesterol (Chol), triglycerides (TG), urea and creatinine. RESULTS: Thirteen hundred eligible Santhals were enlisted. Of them, $1049(80.7 \%)$ participated in the study. The male and female participants were $40 \%$ and $60 \%$, respectively. The prevalence of T2DM was $0.6 \%$ and hyperglycemia (FPG > $5.5 \mathrm{mmol} / \mathrm{l}$ ) was $10.0 \%$. The prevalence of systolic hypertension (sHTN) was $24.4 \%$ and diastolic hypertension (dHTN) was $24.6 \%$. Compared with the males the females had significantly higher prevalence of SHTN (OR, 2.20 with $95 \%$ CI, 1.62 - 3.02) and dHTN (OR, 1.81 with CI, 1.34 2.0); whereas, the prevalence of T2DM and IFG did not differ. Regarding obesity $45 \%$ of the participants had BMI < 18.5 and only 5\% had BMI > 23.1. Logistic regression estimated that the increasing age, female sex, higher FPG $(>5.5 \mathrm{mmol} / \mathrm{l})$ and higher Chol $(>160 \mathrm{mg} / \mathrm{dl})$ had independent risk for SHTN and dHTN. CONCLUSIONS: The Santhals had less risk for diabetes but increased risk for hypertension. The Santhal females had excess risk of hypertension. Advancing age, female *Corresponding author. 
sex, hyperglycemia and hypercholesterolemia were found to have significant risk for hypertension. Obesity had no effect on diabetes or hypertension. High dietary salt intake among Santhals might have contributed to the development of hypertension. Further study may confirm the study findings and to understand why this tribe is less susceptible to diabetes and more to hypertension.

\section{Keywords}

\section{Santhal, Obesity, Diabetes, Hypertension, Lipids}

\section{Introduction}

The increasing trend of Type2 diabetes is common in the developing nations and most common in the Southeast Asian countries [1]. The tribal or aboriginal populations also showed an increase of diabetes worldwide. High prevalence of diabetes was reported among the Native Americans [2]-[6]. The aborigines of Australia had increased prevalence of diabetes and metabolic syndrome leading to diabetic complications like nephropathy [7]. In Africa, the prevalence of diabetes was found high among Danagla community of northern Sudan [8]. In Asia too, an increased prevalence of diabetes, obesity and hypertension was reported among Bedouin origin in the United Arab Emirates [9] and among the Aborigines in Taiwan [10]. One of the tribes in Bangladesh also had higher prevalence of diabetes as compared with Bangladeshi native rural people [11]. Santhal (Santals) tribe is the third largest tribe of India and Bangladesh in Asia [12]. It is thought to be the oldest indigenous tribe that belongs to the Pre Aryan period [12]-[14]. They are mostly found scattered in the states of West Bengal, Bihar, Orissa, Jharkhand and Assam in India, and in the northern-west of Bangladesh. Notwithstanding Santhals are one of the largest and the oldest aboriginal tribes in India and in Bangladesh there has been no known information about the prevalence of diabetes or hypertension in this tribe. This study addressed the prevalence of diabetes and hypertension among the Santhals.

\section{Research Design}

The research proposal was duly approved by the Ethical Review Committee of Bangladesh Diabetic Samity (BADAS); previously known as Diabetic Association of Bangladesh (DAB).

\subsection{The Study Area}

We purposively selected eight villages mostly inhabited by Santhal in Manda Thana under the district of Naogaon adjacent to Rajshahi. It is a 14-hour journey by bus from Dhaka. We conducted the study in the month of December2008 through February 2009.

The selected villages of Santhals were made habitable by their forefathers. The livelihood of their ancestors was hunting and gathering in the forest. Subsequently, their primitive occupation changed to agriculture with gradual reclamation of livable and cultivable land from hilly forest. The ancestors of Santhals were Pre-Aryan and/or Proto-Australoids [12] [13]. The Santhals have been living in this area for generations. Most of them are landless poor dependent on agrarian works for their livelihood.

To begin with the study we consulted the local leaders of Santhal community and the elected members of the Union Council, a Local Government Body. They agreed to participate. The young Santhals volunteered making list of the eligible participants from the Santhal communities. All members of each Santhal family aged 20 years or more were considered eligible. The field workers had considerable discussion with the enlisted participants about the objectives and the details of investigations.

The investigation procedure included: a) interviewing; b) clinical examination; c) anthropometry (height, weight, waist-girth and hip-girth); d) resting blood pressure and e) fasting blood sample. Each participant was interviewed about 1) socio-economic condition e.g. housing, sanitation, education, occupation, physical activity, family income; and 2) family history of chronic illness based on available medical reports and/or verbal autopsy.

The local leaders, the volunteers, and the participants opined that it would be convenient for them to attend 
investigations in two sessions-I) afternoon session: interviewing, anthropometry and clinical examination while spending at leisure, and II) following morning session: they would come with overnight fast for fasting blood samples and resting blood pressure before starting their daily work.

\subsection{Data Collection}

The trained field workers started interviewing session at afternoon for age, sex, education, annual family income and current illness. Known family history of diabetes, hypertension, stroke and coronary heart disease were also noted. Anthropometry included weight, height, waist- and hip-girth. Then, each participant was referred to an adjacent physician's desk for both general and systemic examination for clinical assessment. Each participant was registered with an identification number (ID No). Then s/he was advised to attend the same location in the next morning with an overnight fast for measuring blood pressure and giving fasting blood sample.

Measurements of height, weight, and waist and hip girth were taken with light clothes and without shoes. The weighing tools were calibrated daily by known standard weight. For height, the subject stood in erect posture vertically with the occiput, back, hip, and heels touching the wall behind while gazing horizontally in front and keeping the tragus and lateral orbital margin in the same horizontal plane. Waist girth was measured by placing a plastic tape horizontally mid-way between 12th rib and iliac crest in the mid-axillary line. Similarly, hip was measured by taking the extreme end posteriorly and the symphysis pubis anteriorly. Blood pressure was taken after 10 min rest with standard cuffs for adult, fitted with mercury sphygmomanometer. All types of physical activities-household (e.g. washing, cooking, cleaning, gardening) and outdoor (e.g. ploughing, digging, crop-carrying, harvesting, boat-rowing, manual irrigation etc) were graded according to the intensity and duration of work, from heavy, moderate and mild or sedentary type, based on an equivalent walk of $>90 \mathrm{~min}, 60$ - $90 \mathrm{~min}$ and $<60$ $\mathrm{min} / 24$ hours, respectively [15].

Five $\mathrm{ml}$ of venous blood was taken for fasting plasma glucose, total cholesterol, HDL cholesterol, and triglycerides (TG). We kept generator standby for continuous supply of electricity for the required laboratory investigation. We estimated plasma glucose by the glucose oxidase (enzymatic oxidation) method (GOD/PAP Kit; Randox, Antrim, U.K.) using the auto-analyzer Screen Master-3000 (B.S. Biochemical Analyzer, Arezzo, Italy). We used diagnostic criteria of American Diabetes Association [16]. Systolic and diastolic hypertension were taken as $\geq 135$ and $\geq 85 \mathrm{mmHg}$, respectively.

\subsection{Statistical Analysis}

The comparisons of characteristics (mean with standard deviation) were shown between men and women and between subjects with and without hypertension. The prevalence rates of hypertension (sHTN and dHTN) and diabetes were shown in percentages. The Chi sq test estimated the association of diabetes and hypertension with biophysical risk factors like age, sex, obesity etc. As the prevalence of diabetes was found very low, IFG was taken together to get the total prevalence of hyperglycemia for a meaningful comparison between men and women. Logistic regression was used to quantify the risk factors, which were selected stepwise in different steps taking systolic hypertension (sHTN) as a dependent variable; covariates were sex, age, WHR, FPG, Chol in forward conditional method. All statistical tests were considered significant at a level of $\leq 5 \%$. SPSS version 10.05 was used.

\section{Results}

A total of 1300 Santhals of age 20 years or more from 8 selected villages were enlisted. Of them, 1049 (80.7\%) responded. The male and females participants were $40 \%$ and $60 \%$, respectively.

Most of the participants were from poor social class. Seventy-five percent had daily per capita earning of USD 0.33 or less; only $35 \%$ had access to water-seal latrine and the rest used bore-hole or trench latrine. Of them, $86 \%$ were illiterate, $13.8 \%$ could write his name and address and a total of 5 participants had 10 years schooling. As regards housing, 94\% had single hut covered with corrugated tin shed and the rest were thatched. It was a harvesting period when sedentary or mild type of physical activities was found only in $1.3 \%$, moderate activity in $8.8 \%$ and heavy physical activity in $85.5 \%$. Family history of diabetes, hypertension, sudden death (suspected coronary heart disease) and paralysis were reported in $2.1 \%, 8.5 \%, 1.4 \%$ and $5.2 \%$, respectively. The Santhal people experienced high prevalence of joint swelling (suspected Arthritis 21.6\%) and epigastric pain related 
to meal (suspected peptic ulcer disease 16.5\%). Regarding drug history, about $67.8 \%$ of the participants never used any medicine. Of the female participants of reproductive age, $10.2 \%$ reported using oral contraceptive pills.

Clinical examination revealed that $43.5 \%$ had mild to moderate and $1.4 \%$ had severe degree of anemia. Palpably enlarged liver was found in $1.8 \%$. Two had detectable jaundice with tender and enlarged liver diagnosed as possible viral hepatitis. Two participants had visible goiter and one had dependent pitting edema.

The bio-physical characteristics were compared between male and female participants (Table 1). The mean values with standard deviations (SD) of age, FPG and TG did not differ. Regarding obesity, compared with the females the males were significantly more obese ( $<0.001$ for both BMI \& WHR). In contrast, the means (SD) of SBP, DBP and T-chol were found significantly higher among female than among males.

The characteristics were also compared between hypertensive and non-hypertensive Santhals (Table 2). Compared with the non-hypertensive the hypertensive Santhals had significantly higher means (SD) of age, SBP, DBP, FPG, T-chol, TG and creatinine (for all, $\mathrm{p}<0.001$ ); whereas, BMI and WHR did not differ.

The prevalence of DM was $0.6 \%$ and hyperglycemia (FPG $>5.5 \mathrm{mmol} / \mathrm{l}$ ) was $10.0 \%$ and the prevalence did not differ between men and women. The prevalence of both hypertension (sHTN \& dHTN) and hyperglycemia according to sex were shown in Table 3 . The prevalence of sHTN was $24.4 \%$ and dHTN was $24.6 \%$. Compared with the male the female Santhals had significantly higher prevalence of sHTN (16.2 v. 29.9\%; OR 2.20, 95\% CI, 1.62 - 3.02). Likewise, the prevalence of dHTN was also significantly higher among female than the male participants.

We used logistic regression to quantify the individual effect of sex, age, WHR, FPG and T-chol on systolic hypertension as a dependent variable in forward conditional method (Table 4). These variables were selected because of having significant associations with SBP estimated by partial correlation controlling for age and sex (correlation table not shown). The logistic regression, at the fourth stage, retained the significant effect of female sex (OR 2.43, 95\% CI, 1.68 - 3.52), hyperglycemia (OR 3.2, 95\% CI, 1.99 - 5.14) and hypercholesterolemia (OR 1.90, 95\% CI, 1.35 - 2.67). For age, higher the age more was the risk (age 31 - 45 y: OR 1.78, 95\% CI, 1.15 - 2.76; age > 45: OR 5.93, 95\% CI, 3.85 - 9.11). Obesity (WHR > 0.85) had no effect for hypertension in the Santhal population.

\section{Discussion}

This study appears to be the first of its kind that addressed not only the prevalence of diabetes and hypertension in one of the largest and the oldest aboriginal tribe in India and in Bangladesh but also to report overall health situation and socio-economic backgrounds of Santhal population. It was possible because of the sincere cooperation made by the Santhals in all investigation steps. The response rate was more than $80 \%$. The young Santhal volunteers helped not only preparing the list of the participants but also organizing the entire study-like selecting the sites of investigation in each village, informing the participants about place, date and time, making arrangement

Table 1. Comparison of characteristics between men $(n=419)$ and women $(n=630)$.

\begin{tabular}{|c|c|c|c|c|c|}
\hline \multirow[b]{2}{*}{ Variables } & \multicolumn{2}{|c|}{ Men } & \multicolumn{2}{|c|}{ Women } & \multirow[b]{2}{*}{ p } \\
\hline & Mean & $\mathrm{SD}$ & Mean & $\mathrm{SD}$ & \\
\hline Age (y) & 39.8 & 16.2 & 38.8 & 13.5 & $n s$ \\
\hline BMI & 19.3 & 2.1 & 18.6 & 2.6 & $<0.001$ \\
\hline WHR & 0.88 & 0.05 & 0.83 & 0.07 & $<0.001$ \\
\hline WHtR & 0.44 & 0.04 & 0.44 & 0.05 & $n s$ \\
\hline SBP (mmHg) & 122 & 19 & 130 & 23.1 & $<0.001$ \\
\hline DBP (mmHg) & 78.7 & 11.3 & 81.1 & 11.8 & $=0.001$ \\
\hline FPG (mmol/L) & 4.41 & 0.83 & 4.45 & 0.91 & $n s$ \\
\hline T-chol (mg/dl) & 145 & 30 & 155 & 30 & $<0.001$ \\
\hline Triglycerides (mg/dl) & 96 & 37 & 99 & 41 & $n s$ \\
\hline Urea (mg/dL) & 28.4 & 9.5 & 26.9 & 10.9 & $=0.03$ \\
\hline Creatinine (mg/dl) & 1.1 & 0.25 & 0.95 & 0.33 & $<0.001$ \\
\hline
\end{tabular}

BMI: body mass index; WHR: waist-to-hip ratio; WHtR: waist-to-height ratio; SD: standard deviation; FPG: fasting plasma glucose; SBP, DBP: systolic, diastolic blood pressure; T-chol: total cholesterol; ${ }^{*}$ p: after unpaired t-test (men v. women); ns: not significant. 
Table 2. Comparison of characteristics between subjects with and without systolic hypertension.

\begin{tabular}{|c|c|c|c|c|c|}
\hline & \multicolumn{2}{|c|}{$\begin{array}{c}\text { Non hypertensive } \\
\text { SBP }<135 \mathrm{mmHg}(\mathrm{n}=778)\end{array}$} & \multicolumn{2}{|c|}{$\begin{array}{c}\text { Hypertensive } \\
\mathrm{SBP} \geq 135 \mathrm{mmHg}(\mathrm{n}=255)\end{array}$} & \multirow[t]{2}{*}{${ }^{*} \mathrm{p}$} \\
\hline & Mean & SD & Mean & SD & \\
\hline Age (y) & 36.3 & 12.6 & 48.3 & 16.9 & $<0.001$ \\
\hline BMI & 18.9 & 2.3 & 18.8 & 2.93 & $n s$ \\
\hline WHR & 0.85 & 0.06 & 0.86 & 0.07 & ns \\
\hline WHtR & 0.44 & 0.04 & 0.45 & 0.06 & $<0.001$ \\
\hline SBP (mmHg) & 117 & 9 & 157 & 22 & $<0.001$ \\
\hline DBP (mmHg) & 76 & 8 & 93 & 11 & $<0.001$ \\
\hline FPG (mmol/L) & 4.29 & 0.80 & 4.87 & 0.97 & $<0.001$ \\
\hline T-chol (mg/dl) & 149 & 29 & 160 & 31 & $<0.001$ \\
\hline Triglycerides (mg/dl) & 96 & 38 & 106 & 424 & $=0.001$ \\
\hline Urea (mg/dL) & 26.9 & 8.6 & 28.8 & 14. 6 & $=0.020$ \\
\hline Creatinine (mg/dl) & 1.00 & 0.23 & 1.09 & 0.49 & $<0.001$ \\
\hline
\end{tabular}

BMI: body mass index; WHR: waist-to-hip ratio; WHtR: waist-to-height ratio; SD: standard deviation; FPG: fasting plasma glucose; SBP, DBP: systolic, diastolic blood pressure; T-chol: total cholesterol; ${ }^{*}$ p: after unpaired t-test (non-hypertensive v. hypertensive); ns: not significant.

Table 3. Prevalence of hypertension (systolic \& diastolic: sHTN \& dHTN) and IFG + T2DM.

\begin{tabular}{|c|c|c|c|c|c|c|c|c|}
\hline & $\mathrm{n}$ & sHTN & $\begin{array}{c}\text { OR } \\
{[95 \% \mathrm{CI}]}\end{array}$ & dHTN & $\begin{array}{c}\text { OR } \\
{[95 \% \mathrm{CI}]}\end{array}$ & $\mathrm{n}$ & $\begin{array}{c}\mathrm{IFG}+\mathrm{DM} \\
\mathrm{FPG}>5.5 \mathrm{mmol} / \mathrm{l}\end{array}$ & $\begin{array}{c}\text { OR } \\
{[95 \% \mathrm{CI}]}\end{array}$ \\
\hline Men & 421 & $\begin{array}{c}68 \\
(16.2)\end{array}$ & & $\begin{array}{c}77 \\
(18.3)\end{array}$ & & 366 & $\begin{array}{c}38 \\
(10.4)\end{array}$ & \\
\hline Women & 626 & $\begin{array}{c}187 \\
(29.9)\end{array}$ & $\begin{array}{c}2.20 \\
{[1.62-3.02]}\end{array}$ & $\begin{array}{c}181 \\
(28.9)\end{array}$ & $\begin{array}{c}1.81 \\
{[1.34-2.46]}\end{array}$ & 577 & $\begin{array}{c}63 \\
(10.9)\end{array}$ & $\begin{array}{c}1.11 \\
{[0.69-1.62]}\end{array}$ \\
\hline Total & 1047 & $\begin{array}{c}255 \\
(24.4)\end{array}$ & & $\begin{array}{c}258 \\
(24.6)\end{array}$ & & 943 & $\begin{array}{c}94 \\
(10.0)\end{array}$ & \\
\hline
\end{tabular}

Parenthesis ( ) indicates percentages; [ ] indicates 95\% confidence interval after odds ratio (men v. women) OR: odds ratio.

of transports and so on. There was an effort to avoid bias in selection of a representative sample of the tribes. Considering our logistic support, communication and language gap we had no option other than to trust the list of participants made by the volunteers. This may be the limitation of this study. The other limitations may also be noted that clinical findings of illness (anemia, jaundice, edema, goiter, hepatomegaly) could not be confirmed by laboratory investigation.

There are substantial reports that indicate an increased prevalence of diabetes and/or hypertension among the indigenous or tribal or aboriginal populations [3]-[8]. One of the tribal populations of Bangladesh also showed higher prevalence of diabetes compared to rural Bangladeshis [11]. Obviously, it was hypothesized; the Santhal tribe also might have increased prevalence of diabetes. On the contrary, the Santhals had the lowest prevalence of T2DM (0.6\%) as compared to that of rural (4.3\%), Khagrachari Tribe (6.6\%) and urban (11.2\%) populations of Bangladesh [11] [15] [17]. There has been no available published report on the prevalence of diabetes or hypertension in this pre-Aryan Santhal tribe. So, the findings of this study could not be compared. Very low prevalence of diabetes in this population may possibly be due to their exposure to heavy physical activity and lack of obesity. Of the Santhal participants, $85.5 \%$ were exposed to heavy physical activity, and $90 \%$ of them had BMI $<21.9$ and WHR $<0.93$. Thus, the two most known risk factors for diabetes (physical inactivity and obesity) were found non-existent in the Santhal people. There may be some genetic factor of Santhal origin that have protective role against diabetes or still some other unidentified factor(s) that kept them least prone to develop diabetes. Further study is needed to clarify these unknown factors for better understanding of pathogenesis of diabetes.

About one-fourth of the Santhal people had either systolic (24.4\%) or diastolic (24.6\%) hypertension. This estimate appears to be higher than a comparable population-based study in a rural native population of age 20 years or more, which estimated $14.9 \%$ for systolic and $9.1 \%$ for diastolic hypertension [18]. This is a striking observation. It was difficult to explain why there was an increased prevalence of hypertension despite the 
Table 4. Logistic regression-risk factors selected stepwise in different steps taking systolic hypertension (SHTN) as a dependent variable; covariates are sex, age, WHR, FPG, Chol in forward conditional method.

\begin{tabular}{|c|c|c|c|}
\hline Risk factors & OR & $95 \%$ CI & $\mathrm{p}$ \\
\hline \multicolumn{4}{|l|}{ Step 1} \\
\hline \multicolumn{4}{|l|}{ Age tertile (y) } \\
\hline Age $\leq 30$ & 1 & - & \\
\hline Age 31 - 45 & 1.91 & $1.25-2.92$ & $=0.003$ \\
\hline Age $>45$ & 6.16 & $4.07-9.32$ & $<0.001$ \\
\hline \multicolumn{4}{|l|}{ Step 2} \\
\hline $\operatorname{Sex}(m=1, f=2)$ & 2.56 & $1.79-3.67$ & $<0.001$ \\
\hline \multicolumn{4}{|l|}{ Age tertile (y) } \\
\hline Age $\leq 30$ & 1 & - & \\
\hline Age 31 - 45 & 1.92 & $1.25-2.95$ & $=0.003$ \\
\hline Age $>45$ & 6.60 & $4.32-10.07$ & $<0.001$ \\
\hline \multicolumn{4}{|l|}{ Step 3} \\
\hline $\operatorname{Sex}(m=1, f=2)$ & 2.56 & $1.78-3.69$ & $<0.001$ \\
\hline \multicolumn{4}{|l|}{ Age tertile (y) } \\
\hline Age $\leq 30$ & 1 & - & \\
\hline Age 31 - 45 & 1.85 & $1.20-2.86$ & $=0.006$ \\
\hline Age $>45$ & 6.14 & $4.00-9.43$ & $<0.001$ \\
\hline \multicolumn{4}{|l|}{ FPG (mmol/L) } \\
\hline$(<5.6=1, \geq 5.6=2)$ & 3.26 & $2.04-5.21$ & $<0.001$ \\
\hline \multicolumn{4}{|l|}{ Step 4} \\
\hline $\operatorname{Sex}(m=1, f=2)$ & 2.43 & $1.68-3.52$ & $<0.001$ \\
\hline \multicolumn{4}{|l|}{ Age tertile (y) } \\
\hline Age $\leq 30$ & 1 & - & \\
\hline Age 31 - 45 & 1.78 & $1.15-2.76$ & $=0.010$ \\
\hline Age $>45$ & 5.93 & $3.85-9.11$ & $<0.001$ \\
\hline \multicolumn{4}{|l|}{$\mathrm{FPG}(\mathrm{mmol} / \mathrm{L})$} \\
\hline$(<5.6=1, \geq 5.6=2)$ & 3.20 & $1.99-5.14$ & $<0.001$ \\
\hline \multicolumn{4}{|l|}{ T-chol (mg /dl) } \\
\hline$(<161=1, \geq 161=2)$ & 1.90 & $1.35-2.67$ & $<0.001$ \\
\hline
\end{tabular}

STEPS: Age tertile was entered on step 1, sex on step 2, FPG on step 3 and T-chol on step 4. WHR was found not significant and not included in the eas its association was found. †: risk factors in quintile: BMI: body mass index ( $\mathrm{wt} \mathrm{kg/ht} \mathrm{m} \mathrm{sq),} \mathrm{Quintile-1} \mathrm{is} \mathrm{taken} \mathrm{as} \mathrm{reference} \mathrm{category.} \mathrm{§:} \mathrm{Physical}$ activities: equivalent to "X” min walk/24 hour; excluded from Model 2, 3 \& 4; BMI excluded Model 4: OR: odds ratio, CI: confidence interval.

absence of two known risk factors e.g. physical inactivity and obesity. To quantify the risks for hypertension, logistic regression finally, retained the significant effect of advancing age, female sex, hyperglycemia and hypercholesterolemia; whereas, BMI and WHR had no effect. Again, these findings remained unclear. Possibly, increasing age interacted with hyperglycemia and hypercholesterolemia in female Santhals might have influenced to develop hypertension.

Other possible explanation of hypertension in this population may be their dietary habit. Extensive interview revealed that these hard working people used to take large amount of rice, the cheapest food, to meet their calorie need for their subsistence. They could afford neither fat nor protein, nor even vegetable. They just had to depend simply on common salt and chilies. Thus, high salt intake was found common. When the hypertensive subjects were advised "reducing salt in their diet"- their single question was "Is it possible to take rice without salt?” True indeed, even when the cheapest vegetable curry could not be made accessible, salt was the only alternative for them. So, increased amount of sodium intake might be causally associated with hypertension. High dietary sodium in the heritability of non-modulating essential hypertension has been reported [19]. The Santhal aborigines might have inherited such non-modulating subsets, which needs further investigations for confirmation. 


\section{Conclusion}

The Santhal people were found less prone to develop diabetes but very much susceptible to hypertension and the female Santhals had excess risk of hypertension. Advancing age, female sex, hyperglycemia and hypercholesterolemia were found to have significant risk for hypertension. Obesity was proved to have risk neither for diabetes nor for hypertension. High dietary salt intake might have contributed to the development of hypertension. Further study may be undertaken for confirmation of the study findings.

\section{Acknowledgements}

We are grateful to the Chairman and members of "Valine" Union Council for their active cooperation in conducting the study. They provided us with rooms for laboratory and staying. They also helped introducing our team to the Santhal communities. We are also thankful to the young volunteers, the leaders and the participants of the Santhal communities who helped making participants' list, arranging sites of investigations and interpreting for cordial communication. We are also indebted to Prof AKM Nurul Anwar, the Principal of Ibrahim Medical College for his valuable suggestion and support. Prof Jalaluddin Ashraful Haq was very kind to revise this manuscript.

\section{References}

[1] King, H. and Rewers, M. (1993) Global Estimates for Prevalence of Diabetes Mellitus and Impaired Glucose Tolerance in Adults. Diabetes Care, 16, 157-177. http://dx.doi.org/10.2337/diacare.16.1.157

[2] Rock, M. (2003) Sweet Blood and Social Suffering: Rethinking Cause-Effect Relationships in Diabetes, Distress, and Duress. Medical Anthropology, 22, 131-174. http://dx.doi.org/10.1080/01459740306764

[3] Greenlund, K.J., Valdez, R., Casper, M.L., Rith-Najarian, S. and Croft, J.B. (1999) Prevalence and Correlates of the Insulin Resistance Syndrome among Native Americans. The Inter-Tribal Heart Project. Diabetes Care, 22, 441-447. http://dx.doi.org/10.2337/diacare.22.3.441

[4] Hoehner, C.M., Greenlund, K.J., Rith-Najarian, S., Casper, M.L. and McClellan, W.M. (2002) Association of the Insulin Resistance Syndrome and Microalbuminuria among Nondiabetic Native Americans. The Inter-Tribal Heart Project. Journal of the American Society of Nephrology, 13, 1626-1634. http://dx.doi.org/10.1097/01.ASN.0000015762.92814.85

[5] Burrows, N.R., Geiss, L.S., Engelgau, M.M. and Acton, K.J. (2000) Prevalence of Diabetes among Native Americans and Alaska Natives, 1990-1997: An Increasing Burden. Diabetes Care, 23, 1786-1790. http://dx.doi.org/10.2337/diacare.23.12.1786

[6] Pioro, M.P., Dyck, R.F. and Gillis, D.C. (1996) Diabetes Prevalence Rates among First Nations Adults on Saskatchewan Reserves in 1990: Comparison by Tribal Grouping, Geography and with Non-First Nations People. Canadian Journal of Public Health, 87, 325-328.

[7] Rowley, K.G., Iser, D.M., Best, J.D., O’Dea, K., Leonard, D. and McDermott, R. (2000) Albuminuria in Australian Aboriginal People: Prevalence and Associations with Components of the Metabolic Syndrome. Diabetologia, 43, 1397-1403. http://dx.doi.org/10.1007/s001250051545

[8] Elbagir, M.N., Eltom, M.A., Elmahadi, E.M., Kadam, I.M. and Berne, C. (1998) A High Prevalence of Diabetes Mellitus and Impaired Glucose Tolerance in the Danagla Community in Northern Sudan. Diabetic Medicine, 15, 164-169. http://dx.doi.org/10.1002/(SICI)1096-9136(199802)15:2<164::AID-DIA536>3.0.CO;2-A

[9] El Mugamer, I.T., Ali Zayat, A.S., Hossain, M.M. and Pugh, R.N. (1995) Diabetes, Obesity and Hypertension in Urban and Rural People of Bedouin Origin in the United Arab Emirates. The Journal of Tropical Medicine and Hygiene, 98, 407-415.

[10] Chen, H.D., Shaw, C.K., Tseng, W.P., Chen, H.I. and Lee, M.L. (1997) Prevalence of Diabetes Mellitus and Impaired Glucose Tolerance in Aborigines and Chinese in Eastern Taiwan. Diabetes Research and Clinical Practice, 38, 199205. http://dx.doi.org/10.1016/S0168-8227(97)00104-6

[11] Sayeed, M.A., Mahtab, H., Khanam, P.A., Ahsan, K.A., Banu, A., Bazlur Rashid, A.N.M. and Azad Khan, A.K. (2004) Diabetes and Impaired Fasting Glycemia in the Tribes of Khagrachari Hill-Tracts of Bangladesh. Diabetes Care, 27, 1054-1059. http://dx.doi.org/10.2337/diacare.27.5.1054

[12] Santhal Tribe, Art and Culture of Santhal Tribe, Santhal Tribe in India. http://www.indianmirror.com/tribes/santhaltribes.html

[13] Guha, B.S. (1944) Racial Elements in the Populations. Oxford University Press, Oxford. 
[14] Ghosh, S. and Malik, S.L. (2007) Sex Differences in Body Size and Shape among Santhals of West Bengal. Anthropologist, 9, 143-149.

[15] Sayeed, M.A., Mahtab, H., Khanam, P.A., Latif, Z.A., Ali, S.M.K., Banu, A., Ahren, B. and Azad Khan, A.K. (2003) Diabetes and Impaired Fasting Glycemia in a Rural Population of Bangladesh. Diabetes Care, 26, 1034-1039. http://dx.doi.org/10.2337/diacare.26.4.1034

[16] American Diabetes Association (1997) Report of the Expert Committee on the Diagnosis and Classification of Diabetes Mellitus. Diabetes Care, 20, 1183-1197.

[17] Sayeed, M.A., Mahtab, H., Khanam, P.A., Latif, Z.A., Banu, A. and Azad Khan, A.K. (2007) Prevalence of Diabetes and Impaired Fasting Glucose in Urban Population of Bangladesh. Bangladesh Medical Research Council Bulletin, 33, 1-12.

[18] Sayeed, M.A., Banu, A., Khanam, P.A., Mahtab, H. and Azad Khan, A.K. (2002) Prevalence of Hypertension in Bangladesh: Effect of Socioeconomic Risk on Difference between Rural and Urban Community. Bangladesh Medical Research Council Bulletin, 28, 7-18.

[19] Lifton, R.P., Hopkins, P.N., Williams, R.R., Hollenberg, N.K., Williams, G.H. and Dluhy, R.G. (1989) Evidence for Heritability of Non-Modulating Essential Hypertension. Hypertension, 13, 884-889. http://dx.doi.org/10.1161/01.HYP.13.6.884

\section{Abbreviations}

BMI: body mass index (wt in $\mathrm{kg} / \mathrm{ht}$ in m.sq.);

BP: blood pressure (SBP \& DBP = systolic \& diastolic BP);

CI: confidence interval;

DM: Type 2 diabetes;

FPG: fasting plasma glucose; hyperglycemia (FPG $\geq 5.5 \mathrm{mmol} / \mathrm{l}$ );

HTN: hypertension (sHTN \& dHTN = systolic \& diastolic HTN);

IFG: impaired fasting glucose;

SD: standard deviation;

T-chol: total cholesterol;

TG: triglycerides;

WHR: waist-to-hip ratio. 